\title{
May-Thurner Syndrome: An Anatomic Predisposition to Deep Vein Thrombosis
}

\author{
Wasey Ali Yadullahi Mir ${ }^{1}$, Dhan B. Shrestha ${ }^{1}$, Barun B. Aryal ${ }^{2}$, Victoria Lord $^{3}$, Larissa Verda ${ }^{1}$ \\ 1. Department of Internal Medicine, Mount Sinai Hospital, Chicago, USA 2. Department of Emergency Medicine, BP \\ Smriti Hospital, Kathmandu, NPL 3. Department of Internal Medicine, University of Miami, Palm Beach Gardens, USA
}

Corresponding author: Dhan B. Shrestha, medhan75@gmail.com

\begin{abstract}
May-Thurner syndrome (MTS) is a rare clinical condition caused by extrinsic compression of the left common iliac vein by the right common iliac artery, leading to venous stasis and predisposing to thrombus formation. Here, we present the case of a 39-year-old female with no obviously known other risk factors predisposing to thrombosis who presented with severe left leg pain and swelling for a week. The international normalized ratio was elevated and the venous Doppler study showed extensive thrombosis extending from the left common iliac vein to the common femoral vein and the popliteal vein. She was diagnosed with MTS and treated with catheter-directed mechanical thrombolysis and thrombectomy, along with angioplasty of the left common iliac vein and external iliac vein, with near-complete resolution posttreatment.
\end{abstract}

MTS should be suspected in patients who present with unilateral limb thrombosis regardless of the presence of predisposing factors. Timely management with endovascular procedures is necessary to help prevent other potential life-threatening complications.

Categories: Cardiac/Thoracic/Vascular Surgery, Internal Medicine, Anatomy

Keywords: may-thurner syndrome, deep vein thrombosis, endovascular procedure, iliac vein, iliac artery, mechanical thrombolysis

\section{Introduction}

May-Thurner syndrome (MTS) is an uncommon anatomical condition caused by extrinsic compression of a vein, most commonly the left common iliac vein, by an artery, most commonly the right common iliac artery, against bony structures, most commonly the fifth vertebral body [1]. This leads to venous stasis and predisposes to the formation of deep vein thrombosis (DVT) [2]. Atypical presentations involving other anatomical structures have also been reported, including right-sided MTS [3-5]. MTS is estimated to be present in $2-5 \%$ of cases with lower limb DVT, though the exact prevalence is yet to be established. It is more common in women and the second and third decades of life [6].

Review began 07/16/2021 Review ended 07/19/2021 Published 07/28/2021

\section{() Copyright 2021}

Mir et al. This is an open access article distributed under the terms of the Creative Commons Attribution License CC-BY 4.0., which permits unrestricted use, distribution, and reproduction in any medium, provided the original author and source are credited.
Depending on the degree of compression, individuals can be asymptomatic or have venous spur formation with progression to left lower limb DVT [7]. Symptomatic patients may present with acute left extremity swelling and pain, DVT, venous claudication, venous insufficiency, or ulcerations [6-8]. Diagnosis of MTS involves clinical presentation and imaging. While there are no standardized diagnostic criteria, noninvasive ultrasonography is the preferred initial investigation, and the gold standard for diagnosis is conventional venography with intravascular ultrasonography (IVUS). Management includes endovascular interventions, thrombolysis, open surgery, and medical management [2].

Here, we present the case of a 39-year-old female with left lower extremity DVT and pulmonary embolism without any apparent risk factors for thrombosis, who was successfully treated with catheter-directed mechanical thrombolysis and thrombectomy, along with angioplasty of the left common iliac vein and external iliac vein.

\section{Case Presentation}

A 39-year-old female presented with severe excruciating left leg pain to gentle touch and left leg swelling. She had been diagnosed and treated conservatively with warfarin elsewhere for extensive proximal left lower extremity DVT and a small right lower lobe pulmonary embolism a week before. The patient was hemodynamically stable but was uncomfortable due to severe pain. Her left leg was almost twice the size of her normal right leg. Physical examination showed pitting edema, focal bluish discoloration over the anterior lower shin, visible varicosities, and peripheral pulses detectable only by Doppler ultrasonography. She had exquisite tenderness to palpation in the left leg and pain with passive motion. However, she was able to move her legs. Her body mass index was $26.8 \mathrm{~kg} / \mathrm{m}^{2}$.

Her past medical history was not significant and she denied any history of smoking or illicit drug use. She 


\section{Cureus}

was homeless and had a history of two spontaneous miscarriages in the past with no obvious cause, but she denied a history of any medications including oral contraceptive pills. Family history of hypercoagulable states was absent. Laboratory values including renal function tests and lipid profile were unremarkable except for an international normalized ratio (INR) of 1.6. Human immunodeficiency virus and hepatitis C virus serology were negative. Venous Doppler study showed a large clot extending from the left common iliac vein to the common femoral vein and the popliteal vein. CT venogram of the lower extremity confirmed the clot and showed a small amount of thrombus at the inferior vena cava (IVC)/left common iliac vein junction. The above findings suggested the diagnosis of MTS (Figures 1-3).

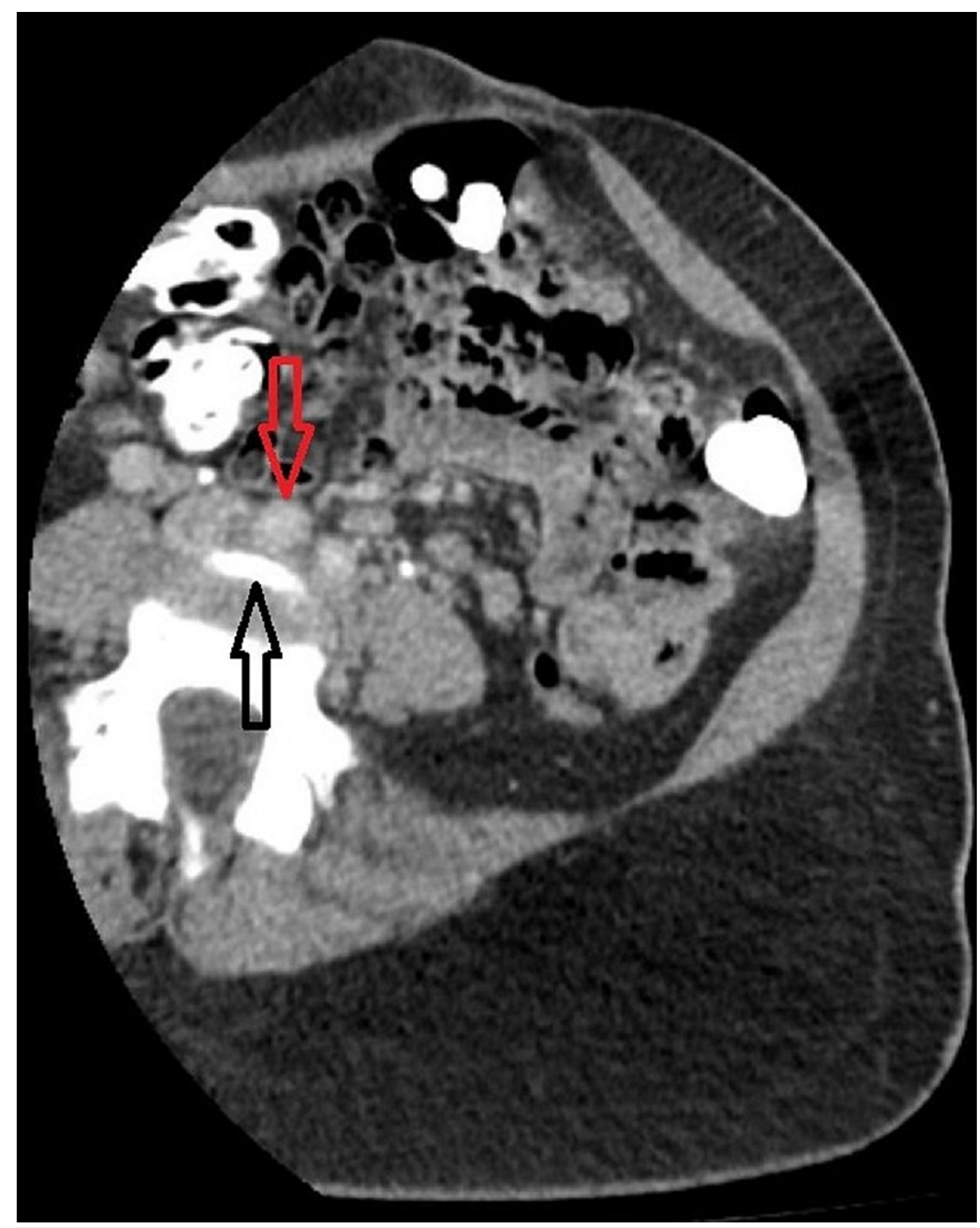

FIGURE 1: Transverse section of CT pelvis showing compression of the left common iliac vein (black arrow) by the right common lliac artery (red arrow) in the pelvis.

CT: computed tomography 


\section{Cureus}

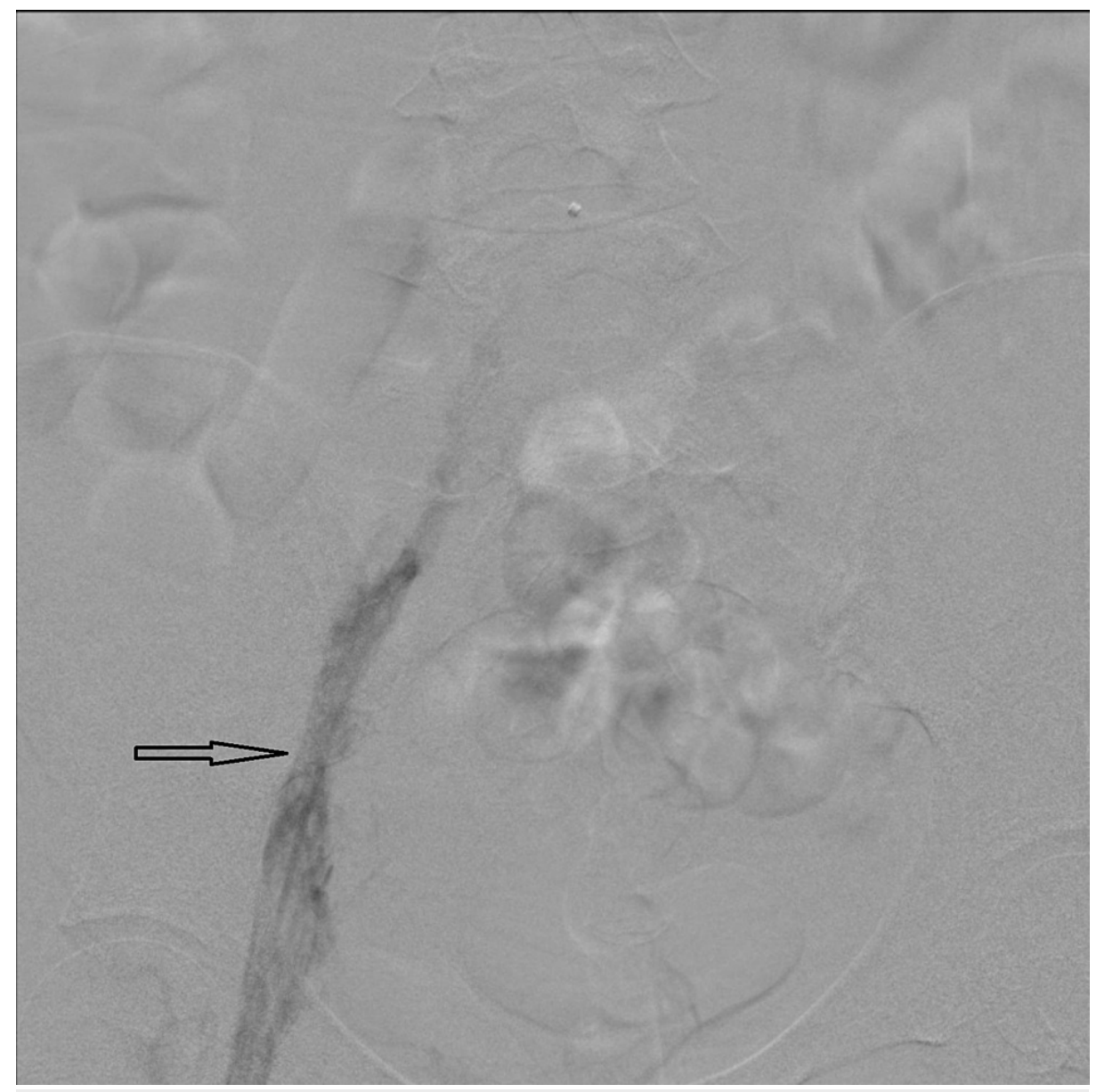

FIGURE 2: Pre-thrombectomy venogram showing thrombus in the left iliac vein extending to the femoral vein (black arrow). 


\section{Cureus}

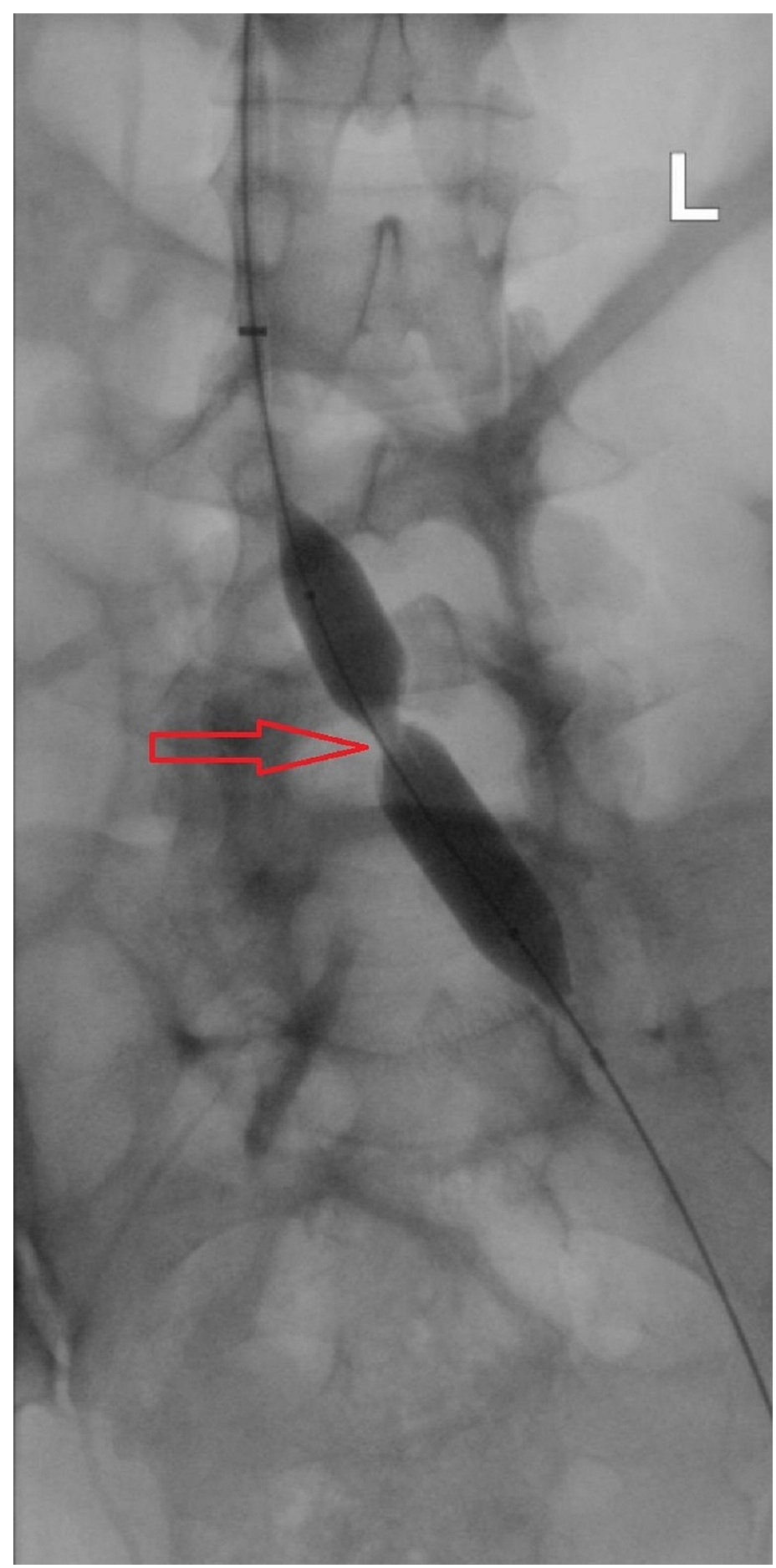

FIGURE 3: Post-thrombolysis and thrombectomy balloon angioplasty with a waist of the balloon (red arrow) due to external compression by the right iliac artery.

As she was a suitable candidate for mechanical thrombolysis and thrombectomy, she underwent catheterdirected mechanical thrombolysis and thrombectomy of the complete left lower extremity venous system and the left common iliac vein on the third day of admission. She was monitored in the intensive care unit postoperatively and had no complications. On the next day, angioplasty was done for high-grade focal narrowing (>90\%) of the left common iliac vein and the external iliac vein, with near-complete resolution post-treatment (Figure 4 ) and no post-procedure complications. After an additional three days of hospital stay, she has discharged on oral apixaban $10 \mathrm{mg}$ twice a day for one week and outpatient follow-up with a hematologist. After the first week, she was kept on apixaban $5 \mathrm{mg}$ twice a day. One month after discharge, she was readmitted for bleeding and a left mid-foot hematoma, which was evacuated on the bedside. She had no recurrence of thrombosis on six months follow-up (Figure 5). Thereafter, she was lost to follow-up. 


\section{Cureus}

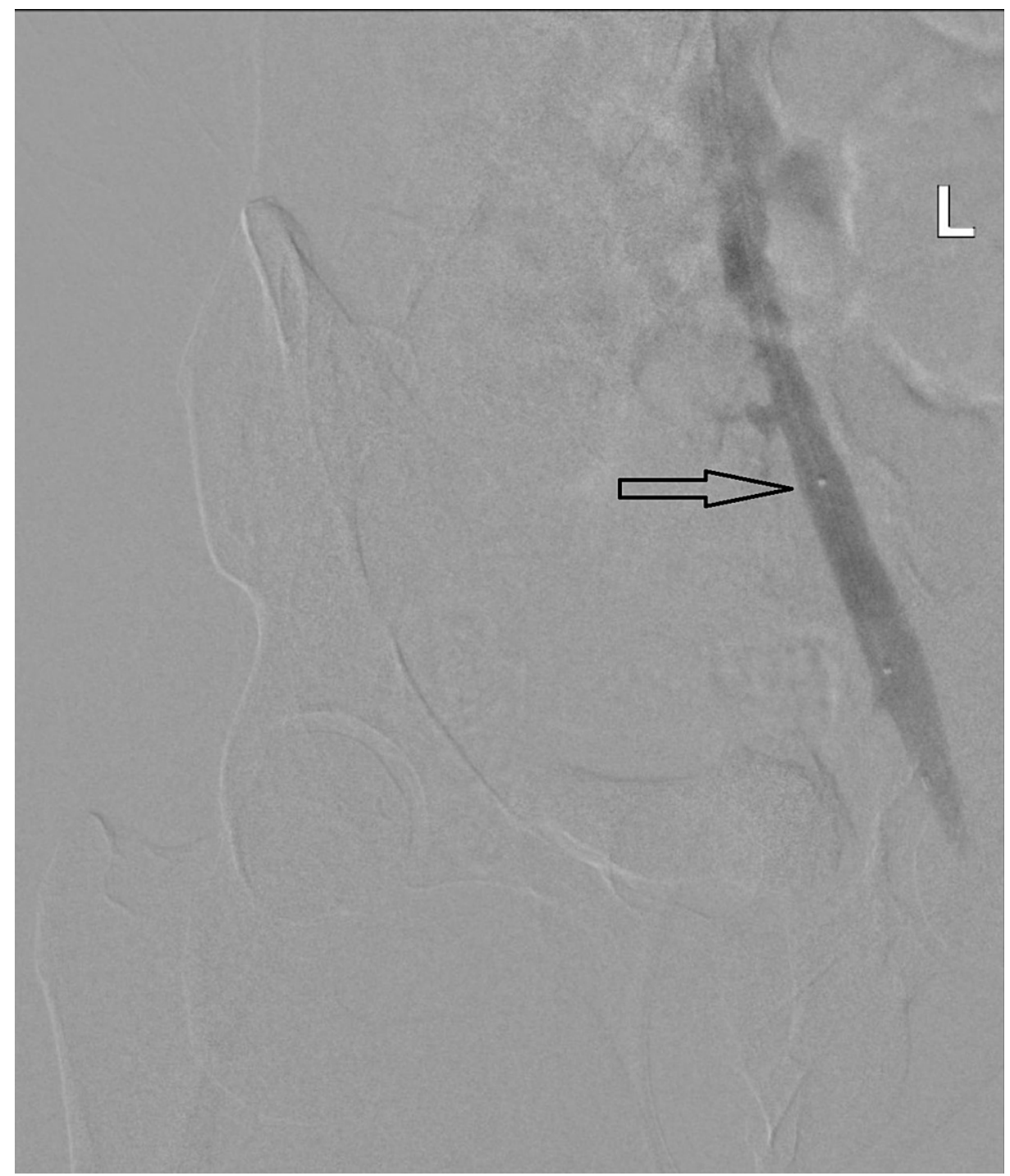

FIGURE 4: Post-angioplasty venogram (black arrow) showing patent flow and minimal residual stenosis. 


\section{Cureus}

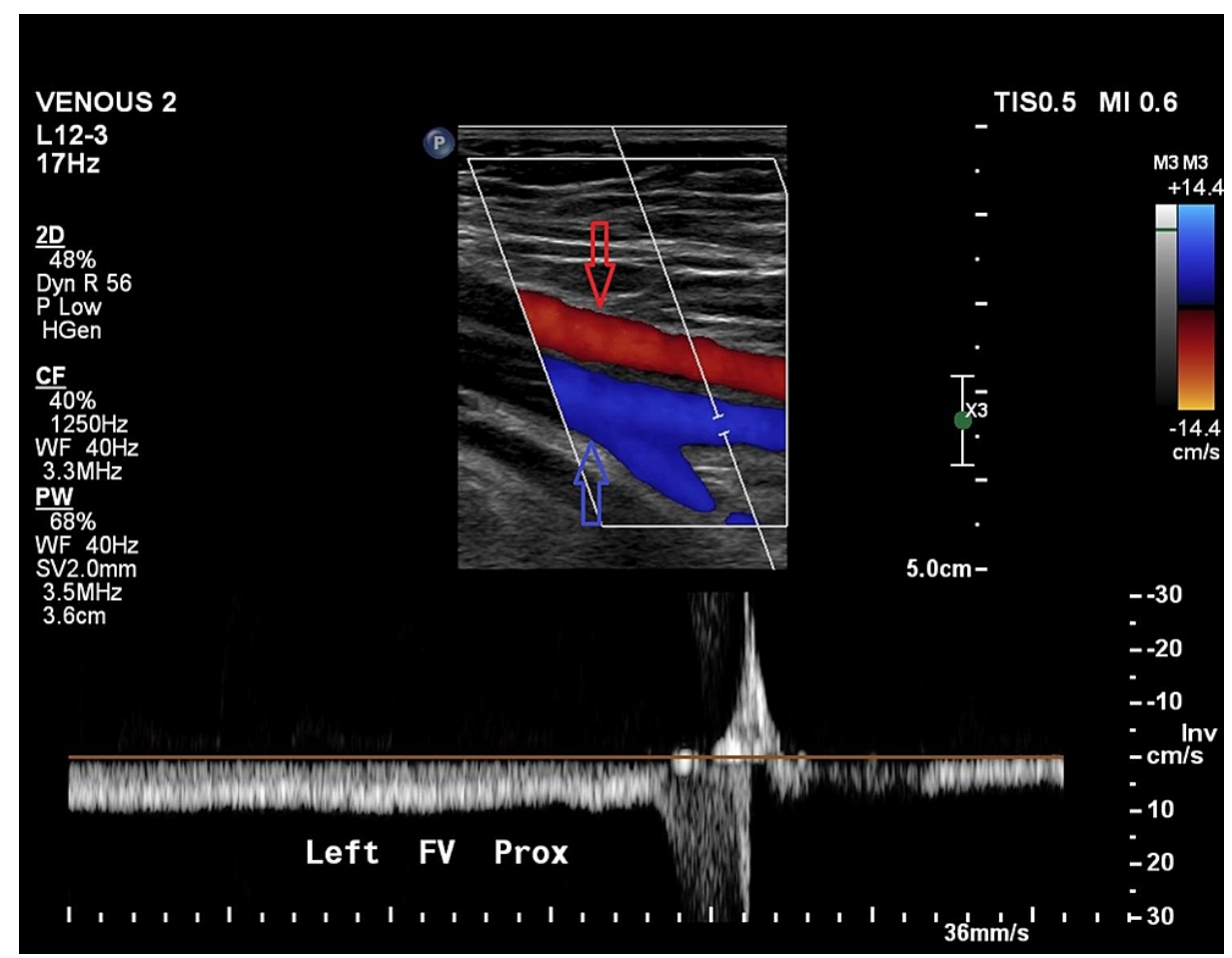

FIGURE 5: Ultrasound of the pelvis on the six-month follow-up showing patency of the vein (blue arrow) with no residual obstruction, with red arrow showing the overlying artery.

\section{Discussion}

DVT is a common and potentially life-threatening condition with an incidence of five per 10,000 individuals per annum in the general population [9]. The frequency of DVT increases with age, with reported incidence rates of 18 per 10,000 individuals per year in the 65-69 age group and 3.1 per 10,000 individuals per annum in the 85-89 age group [10]. It is relatively uncommon in younger age groups before the second decade of life $[9,11]$. DVT usually occurs in the setting of predisposing factors such as recent surgery or trauma, immobilization of limbs, active cancer, acute medical illnesses, obesity, and thrombophilic disorders.

Venous stasis has been long known to be a predisposing factor for thrombosis and is part of the famous Virchow triad along with hypercoagulability and endothelial injury. One cause of venous stasis was first described in 1957 by May and Thurner, who first observed the formation of a "spur-like formation" in the left common iliac vein where it is crossed by the right common iliac artery [1].

In this report, we presented the case of a 39-year-old female with no apparent risk factors for thrombosis. She presented with massive thrombosis of the left lower extremity and pulmonary embolism. Such a presentation should prompt a search for uncommon causes of DVT. In a young female, MTS is an important but often overlooked possibility. A recent review showed that MTS is twice as common in women, and women also tend to present at a younger age and are more likely to present with pulmonary embolism [2].

Early diagnosis and prompt treatment of thrombosis secondary to external iliac vein compression are essential for acute and chronic management of this condition. In the acute setting, the lower extremity duplex ultrasound may not show DVT if the thrombus is more proximal than expected, which can delay diagnosis and initial treatment. Once DVT is diagnosed, the etiology of iliac venous obstruction may be ascertained by a nonphasic flow in the external iliac vein; however, high common iliac vein velocities are a better indicator of compression [12]. IVUS with conventional venography is the gold-standard modality to diagnose MTS. This can provide accurate sizing of luminal diameter and even provide insights into the chronicity of the thrombus [13]. Reversal of blood flow and formation of collaterals may be visualized.

Treatment of MTS is guided by clinical presentation, mainly the presence or absence of thrombosis. Patients without thrombosis can be managed with thrombolysis and stenting, while management of patients with thrombosis includes thrombolysis, stenting, and angioplasty [6]. Open surgery was widely used in the past but has now been replaced by less invasive treatment options. Endovascular procedures such as catheterdirected thrombolysis, stenting, and IVC filter implantation are the preferred choice for treatment $[14,15]$. Our patient was treated with catheter-directed mechanical thrombolysis and thrombectomy, 
followed by angioplasty. She had near-complete resolution of high-grade stenosis post-angioplasty, and additional vascular interventions were not required. After several studies have demonstrated positive results with stenting MTS patients, guidelines from the Society of Interventional Radiology and the Society of Vascular Surgery have been modified to recommend iliac venous stenting in patients who have a compressed external iliac vein [16-18].

\section{Conclusions}

MTS is an anatomical disorder that causes venous stasis in the proximal lower limb and potentially leads to thrombus formation. It should be suspected in young patients, especially women, who present with unexplained DVT in the absence of risk factors for thrombosis. As these cases respond poorly to anticoagulation alone, management with venous angioplasty or stenting, with the removal of thrombus is preferred. Because this is a rare disorder with life-threatening complications such as pulmonary embolism and recurrent thrombosis, a high index of suspicion is warranted for early diagnosis and timely management.

\section{Additional Information \\ Disclosures}

Human subjects: Consent was obtained or waived by all participants in this study. Conflicts of interest: In compliance with the ICMJE uniform disclosure form, all authors declare the following: Payment/services info: All authors have declared that no financial support was received from any organization for the submitted work. Financial relationships: All authors have declared that they have no financial relationships at present or within the previous three years with any organizations that might have an interest in the submitted work. Other relationships: All authors have declared that there are no other relationships or activities that could appear to have influenced the submitted work.

\section{Acknowledgements}

We would like to acknowledge our patient without whom this report would not have been possible. Additionally, we would like to thank all the treating healthcare personal who were involved in patient care.

\section{References}

1. May R, Thurner J: The cause of the predominantly sinistral occurrence of thrombosis of the pelvic veins . Angiology. 1957, 8:419-27. 10.1177/000331975700800505

2. Kaltenmeier CT, Erben Y, Indes I, Lee A, Dardik A, Sarac T, Ochoa Chaar CI: Systematic review of MayThurner syndrome with emphasis on gender differences. J Vasc Surg Venous Lymphat Disord. 2018, 6:399407. 10.1016/j.jvsv.2017.11.006

3. Molloy S, Jacob S, Buckenham T, Khaw KT, Taylor RS: Arterial compression of the right common iliac vein; an unusual anatomical variant. Cardiovasc Surg. 2002, 10:291-2. 10.1016/s0967-2109(01)00139-9

4. Vijayalakshmi IB, Setty HS, Narasimhan C: Unusual cases of right-sided and left-sided May-Thurner syndrome. Cardiol Young. 2015, 25:797-9. 10.1017/S1047951114001115

5. Abboud G, Midulla M, Lions C, El Ngheoui Z, Gengler L, Martinelli T, Beregi JP: "Right-sided" May-Thurner syndrome. Cardiovasc Intervent Radiol. 2010, 33:1056-9. 10.1007/s00270-009-9654-Z

6. Mousa AY, AbuRahma AF: May-Thurner syndrome: update and review. Ann Vasc Surg. 2013, 27:984-95. 10.1016/j.avsg.2013.05.001

7. Knuttinen MG, Naidu S, Oklu R, Kriegshauser S, Eversman W, Rotellini L, Thorpe PE: May-Thurner: diagnosis and endovascular management. Cardiovasc Diagn Ther. 2017, 7:S159-64. 10.21037/cdt.2017.10.14

8. Sedhai YR, Golamari R, Salei A, et al.: May-Thurner syndrome. Am J Med Sci. 2018, 355:510-4. 10.1016/j.amjms.2017.09.011

9. Fowkes FJ, Price JF, Fowkes FG: Incidence of diagnosed deep vein thrombosis in the general population: systematic review. Eur J Vasc Endovasc Surg. 2003, 25:1-5. 10.1053/ejvs.2002.1778

10. Kniffin WD, Baron JA, Barrett J, Birkmeyer JD, Anderson FA: The epidemiology of diagnosed pulmonary embolism and deep venous thrombosis in the elderly. Arch Intern Med. 1994, 154:861-6. 10.1001/archinte.1994.00420080053005

11. Heit JA: The epidemiology of venous thromboembolism in the community . Arterioscler Thromb Vasc Biol. 2008, 28:370-2. 10.1161/ATVBAHA.108.162545

12. Metzger PB, Rossi FH, Kambara AM, et al.: Criteria for detecting significant chronic iliac venous obstructions with duplex ultrasound. J Vasc Surg Venous Lymphat Disord. 2016, 4:18-27. 10.1016/j.jvsv.2015.07.002

13. Forauer AR, Gemmete JJ, Dasika NL, Cho KJ, Williams DM: Intravascular ultrasound in the diagnosis and treatment of iliac vein compression (May-Thurner) syndrome. J Vasc Interv Radiol. 2002, 13:523-7. 10.1016/S1051-0443(07)61535-8

14. Bozkaya H, Cinar C, Ertugay S, Korkmaz M, Guneyli S, Posacioglu H, Parıldar M: Endovascular treatment of iliac vein compression (May-Thurner) syndrome: angioplasty and stenting with or without manual aspiration thrombectomy and catheter-directed thrombolysis. Ann Vasc Dis. 2015, 8:21-8. 10.3400/avd.oa.14-00110

15. Ezhumalai B, Mathur A: May-Thurner syndrome needs to be ruled out in unexplained left-sided deep venous thrombosis: three-tiered endovascular therapy is warranted. IHJ Cardiovasc Case Rep. 2018, 2:73-6. 10.1016/j.ihjecr.2018.01.010

16. Vedantham S, Millward SF, Cardella JF, et al.: Society of Interventional Radiology position statement: 


\section{Cureus}

treatment of acute iliofemoral deep vein thrombosis with use of adjunctive catheter-directed intrathrombus thrombolysis. J Vasc Interv Radiol. 2006, 17:613-6. 10.1097/01.RVI.0000203802.35689.66

17. Meissner MH, Gloviczki P, Comerota AJ, et al.: Early thrombus removal strategies for acute deep venous thrombosis: clinical practice guidelines of the Society for Vascular Surgery and the American Venous Forum. J Vasc Surg. 2012, 55:1449-62. 10.1016/j.jvs.2011.12.081

18. Park JY, Ahn JH, Jeon YS, Cho SG, Kim JY, Hong KC: Iliac vein stenting as a durable option for residual stenosis after catheter-directed thrombolysis and angioplasty of iliofemoral deep vein thrombosis secondary to May-Thurner syndrome. Phlebology. 2014, 29:461-70. 10.1177/0268355513491724 